\title{
Extrahepatic Bile Duct Lymphoma
}

National Cancer Institute

\section{Source}

National Cancer Institute. Extrahepatic Bile Duct Lymphoma. NCI Thesaurus. Code C96952.

A lymphoma that arises from the extrahepatic bile ducts, with the bulk of the disease located at this site. 